\title{
Лuтература
}

Конторович А.Э. и др. (1995) // Геология и геофизика, Т.36, №6, c. $110-126$

Тимошина И.Д. Геохимия органического вещества нефтепроизводящих пород и нефтей верхнего докембрия юга Восточной Сибири. Новосибирск, СО РАН филиал «ГЕО»,2005. 166 c.

\section{ИЗОТОПНАЯ КАНАЛОМИКА ХЕМОАВТОТРОФОВ И ЕЕ РОЛЬ В ИЗОТОПНОЙ ГЕОХИМИИ КАК РЕГУЛЯТОРА ФОРМИРОВАНИЯ МЕСТОРОЖДЕНИЙ МЕТАЛЛОВ И ФАКТОРА ВЫВЕТРИВАНИЯ}

\author{
О.В. Градов
}

Институт Энергетических Проблем Химической Физики им. В.Л. Тальрозе, Российской Академии Наук (ИНЭПХФ РАН) gradov@chph.ras.ru; gradov@center.chph.ras.ru

Практически общеизвестна роль хемоавтотрфов / литотрофов в формировании месторождений и выветривании, однако результаты этой биогеохимической активности и массопереноса, опосредуемого хемоавтотрофами, кардинально различны в зависимости от ионного состава среды, солевых эффектов проводимости и диаграмм Пурбе соответствующих условий указанной активности, а также ряда иных физико-химических характеристик, часто не рассматривающихся как факторы воздействия (для упрощения моделей). Биогеохимические представления раннего периода, на которых базировались модели и кинетические подходы к анализу подобных процессов, являются, по большинству критериев, феноменологическими и «эмпирическими», но не раскрывают суть процессов, происходящих на границе среды, процессируемой микроорганизмами, и поверхности хемоавтотрофов как активных агентов, процессирующих данную среду. Между тем, с точки зрения биохимической физики (и, в частности, биологической кинетики), механизмы, реализующиеся на границе раздела фаз или в 
её диффузионной окрестности, являются определяющими в таких случаях, так как ввод вещества в «микрореакторные» компартменты биологического происхождения и агрегация при биоминерализации, как правило, происходят опосредовано поверхностью биомембраны.

Из специфичности хемоавтотрофов к химически-различным средам можно коррелятивно заключить, что свойства мембраны у них также различны и, как минимум, не противоречат условиям их нахождения в природной минеральной среде. Очевидно, что это прямо связано с механизмами действия мембраны в этой среде. Любые механизмы, определяющие мембранную активность в неорганической среде, по определению, должны являться механизмами взаимодействия этой среды с мембраной, следовательно - механизмами взаимодействия структурных единиц, обеспечивающих трафик неорганических ионов сквозь мембрану (трансмембранный перенос).

Такими структурными единицами являются ионные каналы клетки, точнее их совокупность - т. н. каналом (Publicover, Barratt, 2012), что обеспечивает баланс переноса и специфику в кинетике мембранных процессов. Популяции ионных каналов очень чувствительны не только к окружающей среде, но и к сопряженным с электрофизиологической функцией набором параметров мембран (Labriola et al., 2013); изменение комплексной параметрики каналома хемоавтотрофов приводит, с другой стороны, к изменению эффективности процессов вблизи их поверхности и, как следствие, изменению эффективности биогеохимического процессинга среды.

Отдельные условия могут не только десенсетизировать каналы (Velisetty, Chakrapani, 2012), но и привести к угнетению или гибели популяций клеток хемотрофов, что, естественно, приведет к обнулению эффективности биогеохимического процессинга среды в силу нулевой эффективности ионных каналов.

Известны ионные каналы, взаимодействующие с большинством элементов и взаимодействующих с мембраной агентов в орогенезе, минералогенезе, метаморфизме (и химической тафономии, которой определяется сохранности индикативных образцов 
в стратиграфии / приближенной биоморфологически-опосредованной датировке). Как примеры можно привести структуры каналома, взаимодействующие (по разному и селективно, хотя и не всегда абсолютно) с: Fe (Behera et al., 2014), Mg (Payandeh et al., 2013), Zn (Inoue et al., 2015; Baron et al., 2001), Gd (Elinder, Arhem, 1994), La (Lewis, Spalding, 1998), Cs (Quigley, 2000), гидросульфатом (Czyzewski, Wang, 2012), не говоря об общеизвестных кальциевых, калиевых, натриевых, хлорных каналах и возможности их не абсолютной селективной регуляции отличными от номинальных ионами, соответствующими рядам заместителей и функциям селективности.

Учитывая эволюционно ранний характер и простую физико-химическую реализацию ионоселективных каналов и функций селективности, соответственно, возможно считать, что на достаточно ранних стадиях (например, соответствующих генезису и условиям происхождения джеспеллитов) могли работать каналомы автотрофов, включая не сохранившихся «проблемных» (shadow life) (Ranganathan, 1994; Pohorille et al., 2005).

Учитывая возможности изотопного фракционирования - как углерода (Galimov, 1985), так и неорганических элементов, металлов (предметы компетенции металломики или элементомики (Li et al., 2008), соответственно), в ходе биогеохимической деятельности «планетарной микробиоты», можно гарантировать участие каналома и мембранома литотрофов в биологическом фракционировании изотопов в ходе формирования месторождений и выветривания (предметом мембраномики (Shimanouchi et al., 2009) для данных случаев должна являться совокупность мембран популяции, взаимодействующей посредством ионных каналов и реализующей с их помощью как фильтрующую, сорбционную и биокаталитическую функцию, так и коммуникационную / координирующую массоперенос в гомогенной по некоторому параметру среде или области среды). Нами предлагается использование для целей синхронного измерения активности каналома прокариот и результатов их биогеохимической, а также изотопно-фракционирующей деятельности техник МС-патч-клампа (Gradov, Gradova, 2015) и изотопных методов локальной фиксации потенциала (Pankratov, 2015). 


\title{
Лuтература
}

Baron A. et al. // JBC. 2001, 276(38):35361-35367.

Behera R.K. et al. // PNAS USA, 2014, 111(22):7925-7930.

Czyzewski B.K., Wang D.N. // Nature. 2012, 483(7390):494-497.

Elinder F., Arhem P. // Biophys. J. 1994, 67(1):71-83.

Galimov E.M. The Biological Fractionation of Isotopes // Academic Press Inc., 1985, $282 p$.

Gradov O., Gradova M. // Adv. Biochem., 2015, 3, 66-71.

Inoue K. et al. // Curr. M. Chem., 2015, 22(10):1248-1257.

Labriola J.M. et al. // JBC. 2013, 288(16):11294-11303.

Lewis B.D., Spalding E.P. // J. Membr. Biol. 1998, 162(1):81-90.

Li Y. F. et al. // Pure \& Appl. Chem., 2008, 80(12):2577-2594.

Pankratov S. // Adv. Biochem., 2015, 3, 96-112.

Payandeh J. et al. // Bioch. Bioph. Acta, 2013,1828(11):2778-2792.

Pohorille A. et al. // Astrobiology, 2005, 5(1):1-17.

Publicover S.J., Barratt C.L. // J. Physiol. 2012, 590(11):2553-2554.

Quigley E.P // J. Membr. Biol., 2000, 174(3):207-212.

Ranganathan R. // PNAS USA, 1994, 91(9):3484-3486.

Shimanouchi T. et al. // Membr., 2009, 34(6):342-350.

Velisetty P., Chakrapani S. // JBC. 2012, 287(22):18467-18477.

\section{НОВЫЕ ДАННЫЕ ИЗОТОПНОГО $\left(\delta^{18} \mathrm{O}, \delta^{13} \mathrm{C}\right)$ СОСТАВА КАЛЬЦИТИЗИРОВАННЫХ ХАРОВЫХ ВОДОРОСЛЕЙ}

\author{
Т.П. Митюшева, В.И. Каткова \\ ИГ Коми НЦ УрО РАН (mityusheva@geo.komisc.ru)
}

Исследован изотопный состав харовых водорослей из озер Южного Тимана. Харофиты Chara contraria A. Braun обитают в озере Черманты, вид Chara intermedia A. Braun - в группе озер «Параськины озера». Пробы обызвествленных харофитов и вод отобраны в 2013-2014 гг.

Измерения изотопного состава пород выполнялись в ИГ Коми НЦ УpO РАН в г. Сыктывкаре на массспектрометре Delta VAdvantage, IsotopeRatio MS, аналитик И. В. Смолева. Погрешность измерения $\pm 0.1 \%$ o $(1 \sigma)$. Определения $\delta^{18} \mathrm{O}, \delta \mathrm{D}$ и $\delta^{13} \mathrm{C}\left(\mathrm{HCO}_{3}\right)$ в воде произво- 